\title{
Relationship between Perioperative Cardiovascular Events and Glycated Hemoglobin in Diabetic Patients Undergoing Noncardiac Surgery
}

\author{
Zhengwen Chen, ${ }^{1}$ Shuncai Ding, ${ }^{1}$ Yingchuan Yuan, ${ }^{1}$ Jianhua Du, ${ }^{1}$ and Ling Zhang $\mathbb{D}^{2}$ \\ ${ }^{1}$ Department of Anesthesia, The Second Affiliated Hospital to Xinjiang Medical University, Urumqi 830000, China \\ ${ }^{2}$ Department of Cadre Health Care, People's Hospital of Xinjiang Uygur Autonomous Region, Urumqi 830001, China \\ Correspondence should be addressed to Ling Zhang; cggzhangling@163.com
}

Received 22 May 2020; Revised 24 November 2020; Accepted 8 December 2020; Published 18 December 2020

Academic Editor: Marco Guglielmo

Copyright (c) 2020 Zhengwen Chen et al. This is an open access article distributed under the Creative Commons Attribution License, which permits unrestricted use, distribution, and reproduction in any medium, provided the original work is properly cited.

\begin{abstract}
This retrospective nested case-control study is aimed at investigating the relationship between HbAlc and perioperative cardiovascular events (PCE) in patients with diabetes who underwent complex or moderately complex noncardiac surgery at the Second Affiliated Hospital of Xinjiang Medical University in 2013-2018. The patients were divided into four groups according to HbAlc $\leq 7 \%, 7.1 \%-7.9 \%, 8.0 \%-8.9 \%$, and $\geq 9 \%$. The occurrence of PCE among the groups was compared using univariable and multivariable analyses. Finally, 318 patients were included. There were 90 cases of PCE among the 318 patients; the occurrence rate of PCE was $28.3 \%$. No death occurred. The occurrence rates of PCE in the HbAlc $\geq 8.0 \%-8.9 \%$ and HbAlc $\geq 9.0 \%$ groups were $30.8 \%$ and $35.4 \%$, respectively ( $P<0.001$ vs. the HbAlc $7.1 \%-7.9 \%$ group). The occurrence rate of PCE in the HbAlc $\leq 7 \%$ group was $25.9 \%$ ( $P>0.05$ vs. the HbA1c $7.1 \%-7.9 \%$ group). The multivariable logistic regression analysis showed that the course of diabetes (HbA1c stratification $\leq 7 \%, 7.1 \%-7.9 \%, 8.0 \%-8.9 \%, \geq 9 \%, \mathrm{OR}=3.672,95 \% \mathrm{CI}: 1.552-8.687$ ), HbA1c $(\mathrm{OR}=1.895,95 \% \mathrm{CI}: 1.227-4.830)$, SBP $(\mathrm{OR}=1.194,95 \% \mathrm{CI}: 1.015-2.023)$, and microalbuminuria $(\mathrm{OR}=1.098,95 \% \mathrm{CI}: 1.005-$ 1.023) was independently associated with PCE in diabetic patients. In conclusion, HbAlc levels are related to the incidence of PCE in diabetic patients undergoing complex or moderately complex noncardiac surgery.
\end{abstract}

\section{Introduction}

Diabetes mellitus type 2 (T2DM) is a common endocrine disorder characterized by variable degrees of insulin resistance and deficiency, resulting in hyperglycemia [1]. The worldwide prevalence of $\mathrm{T} 2 \mathrm{DM}$ was $9.0 \%$ in men and $7.9 \%$ in women in 2014 [2] and 8.5\% in the United States in 20162017 [3]. The potential complications of T2DM include cardiovascular disease, neuropathy, nephropathy, retinopathy, and increased mortality [4]. T2DM is often identified through routine screening beginning in middle age or through targeted screening of adults of any age with overweight or obesity and with risk factors such as metabolic syndrome, polycystic ovary syndrome, a history of gestational diabetes, or other concerning familial, clinical, or demographic characteristics [1].
Blood glucose levels represent the short-term glucose burden, while the glycated hemoglobin (HbA1c) levels represent the long-term glycemic burden [1]. HbAlc target of $<7 \%$ is considered a reasonable target in adults [1]. The usual management of diabetes includes lifestyle modifications, weight loss, and hypoglycemic agents substitute for lipidlowing medications such as metformin, sulfonylurea, thiazolidinedione, DDP-4 inhibitors, SGLT2 inhibitor, and GLP-1 agonists $[1,5]$.

Diabetes has been recognized as an independent risk factor for perioperative cardiovascular events (PCE) in patients undergoing cardiac or noncardiac surgery $[6,7]$. Nevertheless, at present, there are only a few reports with inconsistent conclusions about the effect of blood glucose control on the risk of PCE, and previous studies did not perform a detailed stratification of blood glucose control level or further analysis 
of the traditional cardiovascular risk factors $[8,9]$. HbA1c is a good indicator to evaluate the blood glucose level of diabetic patients [1]. Nevertheless, previous studies report conflicting results about the association between HbA1c levels and PCE, with studies reporting an association [9-16] and other reporting a lack of association [17-19].

This study is aimed at investigating the relationship between HbAlc and PCE and identifying factors associated with intraoperative and postoperative cardiovascular events in patients with diabetes undergoing complex or moderately complex noncardiac surgery at a university hospital over a 5year period. The results could provide some help for the clinical and surgical management of such patients.

\section{Material and Methods}

2.1. Study Design and Patients. This was a retrospective nested case-control study of patients with diabetes who underwent complex or moderately complex noncardiac surgery at the Second Affiliated Hospital of Xinjiang Medical University from 2013 to 2018 . The study was approved by the ethics committee of the Second Affiliated Hospital of Xinjiang Medical University (\#XJC201354, approved on March $18,2014)$. The requirement for individual consent was waived by the committee.

The inclusion criteria were (1) diagnosis of T2DM, (2) $\geq 40$ years of age, (3) underwent elective noncardiac surgery under general anesthesia, (4) without a pacemaker, (5) $\mathrm{HbA1c}$ measurement within 3 months before the operation, and (6) with complete data. The exclusion criteria were (1) emergency operation, (2) intraoperative blood loss $\geq 1200$ $\mathrm{mL}$, (3) preoperative hemoglobin $\leq 70 \mathrm{~g} / \mathrm{L}$, (4) received a blood transfusion within 90 days before the operation, (5) operation time $\geq 3.8 \mathrm{~h}$ and intraoperative blood transfusion $\geq 1$ unit, (6) hemodynamic fluctuation $\geq 30 \%$, (7) received small interventional or noninterventional surgery, (8) electrolyte disturbance such as hypokalemia and hypocalcemia during or within 7 days after the operation, or (9) factors that may affect the diagnosis of myocardial ischemia, for example, bundle branch block, preexcitation syndrome, ventricular hypertrophy, drugs inducing ST-T segment changes on ECG, and body position changes that could cause ST-T segment changes on ECG.

2.2. Grouping. According to the HbAlc levels at admission, the patients were divided into the $\mathrm{HbA1C} \leq 7 \%, 7.1 \%-7.9 \%$, $8.0 \%-8.9 \%$, and $\geq 9 \%$ groups. This grouping was based on the results of a nested case-control analysis of the ACCORD trial [20].

2.3. Data Collection. The general data before the operation were recorded: sex, age, American Society of Anesthesiology (ASA) grade, body mass index (BMI), history of smoking, New York Heart Association (NYHA) grade, course and complications of T2DM, history of hypertension, ECG, cardiac color echocardiography, biochemistry, $2 \mathrm{~h}$ postprandial blood glucose, HbAlc, and microalbumin. The occurrence of PCE in the perioperative period (from $30 \mathrm{~min}$ before anesthesia to $48 \mathrm{~h}$ after the operation) was recorded, including severe ventricular arrhythmia, myocardial ischemia, angina pectoris, nonfatal myocardial infarction, acute heart failure, nonfatal cardiac arrest, and cardiac death.

2.4. Anesthesia Method. No drug was used before the operation. Anesthesia induction was performed using an intravenous injection of fentanyl $2-5 \mu \mathrm{g} / \mathrm{kg}$, propofol $1-2 \mathrm{mg} / \mathrm{kg}$, and vecuronium $0.08-0.10 \mathrm{mg} / \mathrm{kg}$. Mechanical ventilation was given after tracheal intubation, with a tidal volume 5$10 \mathrm{~mL} / \mathrm{kg}$ and ventilation frequency $12-15$ times/min, maintaining $\mathrm{PET} \% \mathrm{CO}_{2}$ at $30-40 \mathrm{mmHg}(1 \mathrm{mmHg}=0.133 \mathrm{kPa})$. Anesthesia was maintained using a target plasma concentration of propofol of $2-5 \mu \mathrm{g} / \mathrm{mL}$ and a target plasma concentration of remifentanil of $2.6 \mathrm{ng} / \mathrm{mL}$. Vecuronium was intermittently injected to maintain muscle relaxation. Sufentanil 5-10 $\mu$ g was injected intravenously $30 \mathrm{~min}$ before the end of the operation. At the end of the operation, the sufentanil was stopped, and intravenous analgesia was used.

2.5. Diagnostic Criteria of PCE. (1) Severe ventricular arrhythmia: intraoperative 3-channel dynamic electrocardiogram (DCG) and postoperative ECG showing ventricular extrasystole $\geq 5$ times/min, multifocal or multiform ventricular extrasystole, paired ventricular extrasystole, ventricular tachycardia, R-on-T, atrioventricular block above grade II type 2, and ventricular escape. (2) Myocardial ischemia: postoperative ECG showing obvious ischemic changes compared with before operation. (3) Angina pectoris: clinical symptoms of angina pectoris, and ECG showing ST-segment depression and T-wave inversion. (4) Nonfatal myocardial infarction: related clinical symptoms; DCG showing arrhythmia, mainly ventricular arrhythmia; ECG showing STsegment elevation with arched upward, new pathological Q-wave appearing with T-wave inversion; bloodcTnI concentration $>0.1 \mathrm{ng} / \mathrm{mL}$, blood $\mathrm{CK}-\mathrm{MB}$ activity $>20 \mathrm{U} / \mathrm{L}$. (5) Acute heart failure: clinical manifestations of pulmonary congestion such as dyspnea, moist rale, and wheezing rale in bilateral lungs, and signs of left or right heart dysfunction such as pulmonary circulation and/or systemic circulation congestion, insufficient tissue blood perfusion. (6) Nonfatal cardiac arrest: sudden ventricular fibrillation or cardiac arrest during operation and rebeating after cardiopulmonary resuscitation, but the patient died within 2 days after the operation.

2.6. Statistical Analysis. SPSS 19.0 (IBM, Armonk, NY, USA) was used for statistical analysis. The continuous data are expressed as means \pm standard deviations and were analyzed using ANOVA and Tukey's post hoc test. The categorical data are expressed as numbers and percentages and were analyzed using the chi-square test. All variables with $P$ values $<0.10$ in univariable analyses were included in a multivariable analysis that used PCE as the dependent variable. Twosided $P$ values $<0.05$ were considered statistically significant.

\section{Results}

3.1. Characteristics of the Patients. A total of 1070 patients were initially identified; 200 patients were excluded for the lack of HbAlc data within 3 months before operation; 252 were excluded because of emergency surgery, blood loss, 


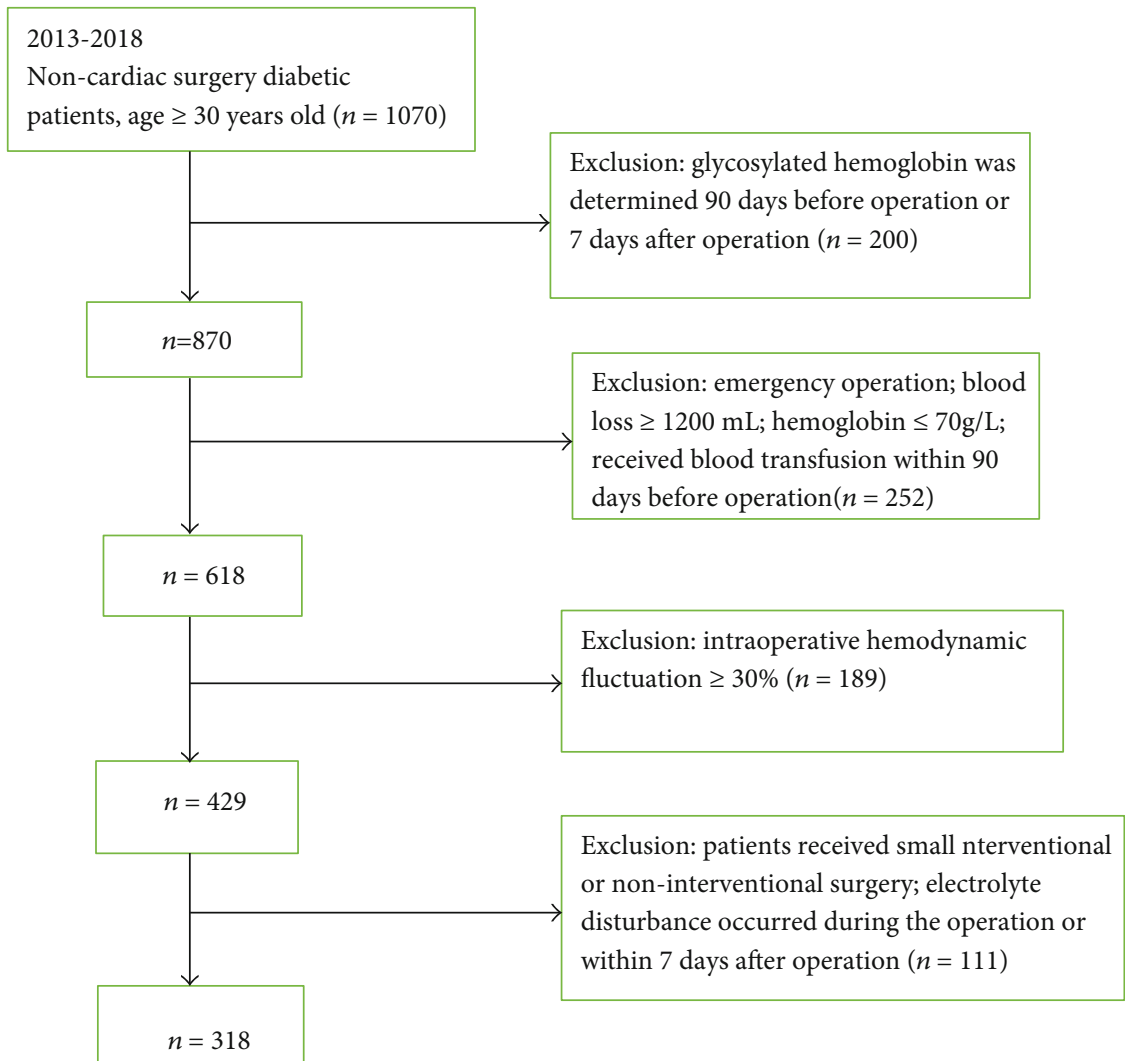

FIgURe 1: Patient flowchart.

low hemoglobin, or blood transfusion; 189 were excluded for hemodynamic fluctuations; and 111 because of the type of surgery (Figure 1). Therefore, 318 patients with a clinical diagnosis of type 2 diabetes, who had complete data and underwent elective noncardiac surgery under general anesthesia, were included in this study. There were 190 males and 128 females. They were 30-78 $(62 \pm 5.6)$ years of age. ASA grade was I-III. There were no significant differences in the course of T2DM, high-density lipoprotein cholesterol (HDL-C) levels, and type of operation among the four groups, but there were differences in age, fasting blood glucose, total cholesterol (TC), triglyceride (TG), low-density lipoprotein cholesterol (LDL-C), diastolic blood pressure (DBP), and systolic blood pressure (SBP) (all $P<0.001$ ) (Table 1).

3.2. Occurrence of PCE. There were 90 cases of PCE among the 318 patients, and the occurrence rate was $28.3 \%$. Among them, the number of patients with myocardial ischemia, serious arrhythmia, serious arrhythmia accompanied by myocardial ischemia, and nonfatal myocardial infarction was 51 $(56.7 \%, 51 / 90), 31(34.4 \%, 31 / 90)$, six $(6.7 \%, 6 / 90)$, and two $(2.2 \%, 2 / 90)$, respectively. No death occurred. The occurrence rate of PCE in the $\mathrm{HbA} 1 \mathrm{c} 7.1 \%-7.9 \%$ group was $20 \%$. The occurrence rates of PCE in the $\mathrm{HbA} 1 \mathrm{c} \geq 8.0 \%-8.9 \%$ and $\mathrm{HbA} 1 \mathrm{c} \geq 9.0 \%$ groups were $30.8 \%$ and $35.4 \%$, respectively, and the differences were statistically significant compared with the HbAlc $7.1 \%-7.9 \%$ group $(P<0.001)$. The occur- rence rate of $\mathrm{PCE}$ in the $\mathrm{HbA1c} \leq 7 \%$ group was $25.9 \%$, but the difference was not statistically significant compared with the HbA1c 7.1\%-7.9\% group (Table 2).

3.3. Multivariable Analysis. The course of diabetes, HbA1c stratification, BMI, SBP, DBP, age, and microalbuminuria were associated with PCE in the univariable analyses. The multivariable logistic regression analysis showed that the course of diabetes (HbA1c stratification $\leq 7 \%, 7.1 \%-7.9 \%$, $8.0 \%-8.9 \%, \geq 9 \%, \mathrm{OR}=3.672,95 \% \mathrm{CI}: 1.552-8.687), \mathrm{HbA} 1 \mathrm{c}$ $(\mathrm{OR}=1.895,95 \% \mathrm{CI}: 1.227-4.830), \mathrm{SBP}(\mathrm{OR}=1.194,95 \%$ CI: $1.015-2.023$ ), and microalbuminuria ( $\mathrm{OR}=1.098,95 \%$ CI: 1.005-1.023) were independently associated with PCE in diabetic patients (Table 3 ).

3.4. Occurrence of Diabetic Complications and Comorbidities. Table 4 shows that higher HbAlc levels were associated with coronary heart disease $(P=0.02)$, diabetic nephropathy $(P=0.02)$, and decreased cardiac function $(P=0.003)$. Moreover, with the increase of $\mathrm{HbA1c}$, the cooccurrence of at least two complications increased gradually $(P=0.001)$.

\section{Discussion}

Diabetes has been recognized as an independent risk factor for PCE in patients undergoing cardiac and noncardiac surgeries [7], but the conclusions regarding the association between HbA1c levels and PCE are conflicting [9-19]. 
TABLE 1: Comparison of the characteristics of the subjects among the four groups.

\begin{tabular}{|c|c|c|c|c|c|}
\hline & $\begin{array}{c}\mathrm{HbAlc} \leq 7.0 \% \\
n=77\end{array}$ & $\begin{array}{c}\text { HbAlc } 7.1 \%-7.9 \% \\
n=110\end{array}$ & $\begin{array}{c}\text { HbAlc } 8.0 \%-8.9 \% \\
n=80\end{array}$ & $\begin{array}{c}\mathrm{HbA} 1 \mathrm{c} \geq 9 \% \\
n=50\end{array}$ & $P$ \\
\hline Age (years) & $52.2 \pm 6.0$ & $51.8 \pm 6.6$ & $54.8 \pm 6.1$ & $56.8 \pm 6.8$ & $<0.001$ \\
\hline Course of disease (years) & $6.5 \pm 2.5$ & $6.6 \pm 1.8$ & $6.6 \pm 2.1$ & $6.6 \pm 2.3$ & 0.06 \\
\hline FPG (mmol/L) & $6.86 \pm 0.94$ & $7.28 \pm 1.10$ & $7.99 \pm 1.20$ & $11.8 \pm 1.8$ & $<0.001$ \\
\hline TG (mmol/L) & $1.49 \pm 0.60$ & $1.56 \pm 0.61$ & $1.67 \pm 0.76$ & $1.80 \pm 0.77$ & $<0.001$ \\
\hline $\mathrm{TC}(\mathrm{mmol} / \mathrm{L})$ & $4.60 \pm 0.80$ & $4.68 \pm 0.80$ & $4.78 \pm 0.88$ & $4.93 \pm 0.87$ & $<0.001$ \\
\hline LDL-C (mmol/L) & $0.99 \pm 0.19$ & $1.01 \pm 0.24$ & $1.03 \pm 0.28$ & $1.07 \pm 0.27$ & $<0.001$ \\
\hline $\mathrm{HDL}-\mathrm{C}(\mathrm{mmol} / \mathrm{L})$ & $1.27 \pm 0.28$ & $1.18 \pm 0.26$ & $1.15 \pm 0.34$ & $1.15 \pm 0.31$ & 0.07 \\
\hline SBP (mmHg) & $136 \pm 14$ & $137 \pm 0.14$ & $142 \pm 18$ & $143 \pm 16$ & $<0.001$ \\
\hline $\mathrm{DBP}(\mathrm{mmHg})$ & $74 \pm 7$ & $75 \pm 6$ & $76 \pm 5$ & $79 \pm 8$ & $<0.001$ \\
\hline \multicolumn{6}{|l|}{ Type of operation } \\
\hline Abdomen & $15(19.4 \%)$ & $25(22.7 \%)$ & $16(20 \%)$ & $11(22 \%)$ & 0.91 \\
\hline Chest & $16(20.7 \%)$ & $22(20 \%)$ & $18(22.5 \%)$ & $9(18 \%)$ & 0.91 \\
\hline Bone & $20(25.9 \%)$ & $25(22.7 \%)$ & $17(21.2 \%)$ & $12(24 \%)$ & 0.71 \\
\hline Urinary system & $12(15.6 \%)$ & $17(15.4 \%)$ & $17(21.2 \%)$ & $9(18 \%)$ & 0.24 \\
\hline Others & $14(18.1)$ & $21(19.0 \%)$ & $12(15 \%)$ & $9(18 \%)$ & 0.92 \\
\hline
\end{tabular}

HbAlc: glycated hemoglobin; FPG: fasting plasma glucose; TG: triglyceride; TC: total cholesterol; LDL-C: low-density lipoprotein cholesterol; HDL-C: highdensity lipoprotein cholesterol; SBP: systolic blood pressure; DBP: diastolic blood pressure.

TABle 2: Perioperative cardiovascular events among the HbAlc groups.

\begin{tabular}{lcccc}
\hline \multirow{2}{*}{ Events } & HbA1c $\leq 7 \%$ & HbA1c & HbA1c & HbA1c $\geq 9 \%$ \\
& $n=77$ & $n=110$ & $n=80$ & $n=51$ \\
\hline Yes & $20(25.9 \%)$ & $22(20 \%)$ & $25(30.8 \%)$ & $18(35.3 \%)$ \\
No & $55(74.1 \%)$ & $88(80 \%)$ & $55(69.2 \%)$ & $33(64.7 \%)$ \\
\hline
\end{tabular}

Events: perioperative cardiovascular event; HbAlc: glycated hemoglobin.

TABLE 3: Multivariable and unconditional logistic regression analysis of the factors associated with perioperative cardiovascular events.

\begin{tabular}{|c|c|c|c|c|}
\hline & \multicolumn{3}{|c|}{$\begin{array}{l}\text { 95\% confidence interval of } \\
\text { OR }\end{array}$} & \multirow[t]{2}{*}{$P$} \\
\hline & & Lower limit & Higher limit & \\
\hline Long course of disease & 3.672 & 1.552 & 8.687 & 0.003 \\
\hline HbAlc & 1.895 & 1.227 & 4.830 & 0.001 \\
\hline SBP & 1.195 & 1.015 & 2.023 & 0.006 \\
\hline Microalbuminuria & 1.098 & 1.005 & 1.023 & 0.017 \\
\hline
\end{tabular}

OR: odds ratio; HbAlc: glycated hemoglobin; SBP: systolic blood pressure.

Therefore, this study is aimed at investigating the relationship between HbAlc and PCE in patients with diabetes who underwent complex or moderately complex noncardiac surgery. The results strongly suggest that $\mathrm{HbAlc}$ levels are related to the incidence of PCE in diabetic patients undergoing complex or moderately complex noncardiac surgery.
There is increasing evidence that diabetes, or even impaired glucose tolerance, can increase the risk of death and perioperative cardiovascular events in patients undergoing noncardiac surgery $[7,15,21]$, but there is still a lack of clear conclusion on the effect of different blood glucose control levels on the occurrence of PCE. Blood glucose levels change rapidly within a single day and represent glycemic control at a single time point. Blood glucose levels are associated with perioperative and postoperative complications, especially because anesthesia can increase blood glucose levels $[22,23]$, but they do not represent the actual longterm glycemic control. On the other hand, HbAlc levels represent the overall glycemic control over the past 3 months and are better indicators of the general diabetes condition in a given patient $[1,24]$. Carson et al. [25] conducted a large population-based cohort study to assess the relationship between diabetes and $\mathrm{HbAlc}$ and the risk of intracerebral hemorrhage (ICH), and the results showed that $\mathrm{HbAlc}$ had a nonlinear J-shaped relationship with ICH in diabetic patients (nonlinear $P=0.0186$ ). Compared with the fourth $\mathrm{HbAlc}$ decile of $6.5 \%-6.7 \%$, the HR of ICH in patients with the lowest $\mathrm{HbAlcdecile} \leq 6.0 \%$ and the highest $\mathrm{HbAlc}$ decile $>9.3 \%(>78 \mathrm{mmol} / \mathrm{mol})$ was 1.27 and 2.19 , respectively. The conclusion was that the increased risk of diabetes-related ICH was directly related to the course of diabetes. The relationship between intracerebral hemorrhage and HbAlc appears to have a "J" shape, indicating that both poor and extremely intensive diabetes control might be associated with an increased risk of stroke. Kotfis et al. [26] showed that elevated HbAlc levels are associated with postoperative delirium regardless of the diagnosis of diabetes. Those results are supported by previous studies [9-16] but contradict others [17-19]. Differences in patient 
TABLE 4: Comparison of the occurrence of diabetic complications and comorbidities among subjects in the four groups.

\begin{tabular}{|c|c|c|c|c|c|}
\hline & $\begin{array}{c}\mathrm{HbA} 1 \mathrm{c} \leq 7 \% \\
n=77\end{array}$ & $\begin{array}{c}\text { HbAlc } 7.1-7.9 \% \\
n=110\end{array}$ & $\begin{array}{c}\text { HbAlc } 8.0-8.9 \% \\
n=25\end{array}$ & $\begin{array}{c}\mathrm{HbA} 1 \mathrm{c} \geq 9 \% \\
n=18\end{array}$ & $P$ \\
\hline Hypertension & $28 \%$ & $26 \%$ & $30 \%$ & $29 \%$ & 0.25 \\
\hline Coronary heart disease & $41 \%$ & $32 \%$ & $36 \%$ & $46 \%$ & 0.02 \\
\hline Nephropathy & $1.8 \%$ & $2.8 \%$ & $2.2 \%$ & $3.7 \%$ & 0.02 \\
\hline Cerebrovascular disease & $4.4 \%$ & $3.9 \%$ & $4.1 \%$ & $4.5 \%$ & 0.22 \\
\hline $\mathrm{EF}<50 \%$ & $3.9 \%$ & $6.4 \%$ & $6.3 \%$ & $6.9 \%$ & 0.003 \\
\hline$\geq 2$ complications & $14.2 \%$ & $15.4 \%$ & $15.8 \%$ & $21.8 \%$ & 0.001 \\
\hline
\end{tabular}

HbAlc: glycated hemoglobin; EF: ejection fraction.

characteristics, ethnicity, and genetics might be involved in the discrepancies.

Previous studies found that emergency operation, operation time $\geq 3.8 \mathrm{~h}$, intraoperative blood transfusion $\geq 1$ unit, and hemodynamic fluctuation $\geq 30 \%$ were independent risk factors of PCE $[8,15,21,25,27]$. Therefore, in order to eliminate those confounding factors, patients fitting those criteria were excluded. The results showed that the incidence of PCE was as high as $30.8 \%$ in patients with the worst glucose control $(\mathrm{HbAlc} \geq 9 \%)$ compared with those with HbAlc 7.0\%-7.9\%. Meanwhile, although nonsignificant, the patients with $\mathrm{HbAlc}<7.0 \%$ showed a slightly higher PCE rate than the HbAlc 7.0\%-7.9\%, suggesting a J-shaped curve.

Myocardial ischemia was the most common PCE in diabetic patients in the present study, as supported by previous studies $[6,28,29]$. Severe myocardial ischemia immediately causes symptoms of angina pectoris and can lead to dismal outcomes. One of the vascular complications in diabetic patients is intradermal cell proliferation of the vascular wall and subendothelial fibrosis with elastic fiber proliferation, leading to coronary artery lumen contraction [30]. Glycated metabolites could increase the secretion of vasoconstrictor factors while decreasing the secretion of endogenous vasodilator factors such as NO [25]. In addition, the disturbance of the cardiac autonomic nerve increases the oxygen consumption of the myocardium, further aggravating myocardial ischemia [31].

The patients in the highest $\mathrm{HbAlc}$ group were older and had higher cardiovascular risk factors, including higher LDLC, TG, TC, SBP, and DBP, which is supported by the literature $[32,33]$. The high levels of HbAlc represent the poor control of blood glucose over the past 3 months $[1,24]$. The hyperglycemia in diabetic patients damages the vascular endothelial cells, increases platelet activity, and abnormal lipid and protein metabolism increases the coagulation state and viscosity, and increases the oxygen free radicals, leading to microcirculation issues and tissue hypoxia, promoting atherosclerosis of large blood vessels such as coronary artery and cerebral vessels, and elevating the blood pressure [34]. Lipid metabolism disturbances are also related to insulin resistance [35].

This study is the first to assess the relationship between blood glucose control and PCE in patients who underwent noncardiac surgery, but there are still some limitations to this study. First, this is a single-center study. Second, many patients who met the diagnostic criteria were excluded because of the lack of HbAlc data, resulting in a small sample size. Third, even if most patients had HbAlc measured on the day of admission, HbAlc was measured 2-3 months before the operation in some patients. Fourth, the incidence of hypoglycemia was not analyzed, and the factors of some antiatherosclerotic drugs on PCE were not evaluated. Therefore, further research is needed to determine the recommended objective of blood glucose control.

\section{Conclusions}

$\mathrm{HbAlc}$ levels are related to the incidence of PCE in diabetic patients undergoing complex or moderately complex noncardiac surgery.

\section{Data Availability}

The data used to support the findings of this study are available from the corresponding author upon request.

\section{Conflicts of Interest}

The authors declare that there is no conflict of interest regarding the publication of this paper.

\section{Acknowledgments}

This study was supported by the Xinjiang Medical University 2013 Research and Innovation Fund (grant number XJC201354).

\section{References}

[1] "Introduction: standards of medical care in diabetes-2020," Diabetes Care, vol. 43, Supplement 1, pp. S1-S2, 2019.

[2] NCDRF Collaboration, "Worldwide trends in diabetes since 1980: a pooled analysis of 751 population-based studies with 4.4 million participants," The Lancet, vol. 387, pp. 15131530, 2016.

[3] G. Xu, B. Liu, Y. Sun et al., "Prevalence of diagnosed type 1 and type 2 diabetes among US adults in 2016 and 2017: population based study," BMJ, vol. 362, article k1497, 2018. 
[4] American Diabetes Association, "8. Obesity management for the treatment of type 2 diabetes: standards of medical care in diabetes-2019," Diabetes Care, vol. 42, pp. S81-S89, 2019.

[5] A. Qaseem, M. J. Barry, L. L. Humphrey, M. A. Forciea, and for the Clinical Guidelines Committee of the American College of Physicians, "Oral pharmacologic treatment of type 2 diabetes mellitus: a clinical practice guideline update from the American College of Physicians," Annals of Internal Medicine, vol. 166, pp. 279-290, 2017.

[6] C. C. Yeh, C. C. Liao, Y. C. Chang et al., "Adverse outcomes after noncardiac surgery in patients with diabetes: a nationwide population-based retrospective cohort study," Diabetes Care, vol. 36, pp. 3216-3221, 2013.

[7] M. Biteker, A. Dayan, M. M. Can et al., "Impaired fasting glucose is associated with increased perioperative cardiovascular event rates in patients undergoing major noncardiothoracic surgery," Cardiovascular Diabetology, vol. 10, p. 63, 2011.

[8] C. Andersson, L. van Gaal, I. D. Caterson et al., "Relationship between $\mathrm{HbA1c}$ levels and risk of cardiovascular adverse outcomes and all-cause mortality in overweight and obese cardiovascular high-risk women and men with type 2 diabetes," Diabetologia, vol. 55, pp. 2348-2355, 2012.

[9] A. Ouattara, P. Lecomte, Y. Le Manach et al., "Poor intraoperative blood glucose control is associated with a worsened hospital outcome after cardiac surgery in diabetic patients," Anesthesiology, vol. 103, pp. 687-694, 2005.

[10] R. Latham, A. D. Lancaster, J. F. Covington, J. S. Pirolo, and C. S. Thomas Jr., "The association of diabetes and glucose control with surgical-site infections among cardiothoracic surgery patients," Infection Control and Hospital Epidemiology, vol. 22, pp. 607-612, 2001.

[11] H. L. Lazar, S. R. Chipkin, C. A. Fitzgerald, Y. Bao, H. Cabral, and C. S. Apstein, "Tight glycemic control in diabetic coronary artery bypass graft patients improves perioperative outcomes and decreases recurrent ischemic events," Circulation, vol. 109, pp. 1497-1502, 2004.

[12] M. E. Halkos, J. D. Puskas, O. M. Lattouf et al., "Elevated preoperative hemoglobin A1c level is predictive of adverse events after coronary artery bypass surgery," The Journal of Thoracic and Cardiovascular Surgery, vol. 136, pp. 631640, 2008.

[13] O. Cohen, R. Dankner, A. Chetrit et al., "Multidisciplinary intervention for control of diabetes in patients undergoing coronary artery bypass graft (CABG)," Cardiovascular Surgery, vol. 11, pp. 195-200, 2003.

[14] C. Iavazzo, M. McComiskey, M. Datta et al., "Preoperative HBA1c and risk of postoperative complications in patients with gynaecological cancer," Archives of Gynecology and Obstetrics, vol. 294, pp. 161-164, 2016.

[15] F. Jehan, M. Khan, J. V. Sakran et al., "Perioperative glycemic control and postoperative complications in patients undergoing emergency general surgery," The Journal of Trauma and Acute Care Surgery, vol. 84, pp. 112-117, 2018.

[16] P. H. Yong, L. Weinberg, N. Torkamani et al., "The presence of diabetes and higher HbAlc are independently associated with adverse outcomes after surgery," Diabetes Care, vol. 41, pp. 1172-1179, 2018.

[17] B. Aydinli, A. Demir, H. Ozmen, O. Vezir, U. Unal, and M. Ozdemir, "Can pre-operative HbAlc values in coronary surgery be a predictor of mortality?," Turkish Journal of Anaesthesiology and Reanimation, vol. 46, pp. 184-190, 2018.
[18] N. Singh, C. Zeng, J. P. Lewinger et al., "Preoperative hemoglobin A1c levels and increased risk of adverse limb events in diabetic patients undergoing infrainguinal lower extremity bypass surgery in the Vascular Quality Initiative," Journal of Vascular Surgery, vol. 70, article e1221, pp. 12251234, 2019.

[19] G. Kranenburg, Y. van der Graaf, J. van der Leeuw et al., "The relation between $\mathrm{HbAlc}$ and cardiovascular events in patients with type 2 diabetes with and without vascular disease," Diabetes Care, vol. 38, pp. 1930-1936, 2015.

[20] D. C. Colayco, F. Niu, J. S. McCombs, and T. C. Cheetham, "A1C and cardiovascular outcomes in type 2 diabetes: a nested case-control study," Diabetes Care, vol. 34, pp. 77-83, 2011.

[21] K. Ogurtsova, J. D. da Rocha Fernandes, Y. Huang et al., "IDF Diabetes Atlas: global estimates for the prevalence of diabetes for 2015 and 2040," Diabetes Research and Clinical Practice, vol. 128, pp. 40-50, 2017.

[22] J. Wang, K. Chen, X. Li et al., "Postoperative adverse events in patients with diabetes undergoing orthopedic and general surgery," Medicine, vol. 98, article e15089, 2019.

[23] E. W. Duggan, K. Carlson, and G. E. Umpierrez, "Perioperative hyperglycemia management: an update," Anesthesiology, vol. 126, pp. 547-560, 2017.

[24] M. Krhac and M. V. Lovrencic, "Update on biomarkers of glycemic control," World Journal of Diabetes, vol. 10, pp. 1-15, 2019.

[25] J. L. Carson, P. M. Scholz, A. Y. Chen, E. D. Peterson, J. Gold, and S. H. Schneider, "Diabetes mellitus increases short-term mortality and morbidity in patients undergoing coronary artery bypass graft surgery," Journal of the American College of Cardiology, vol. 40, pp. 418-423, 2002.

[26] K. Kotfis, A. Szylinska, M. Listewnik, M. Brykczynski, E. W. Ely, and I. Rotter, "Diabetes and elevated preoperative HbA1c level as risk factors for postoperative delirium after cardiac surgery: an observational cohort study," Neuropsychiatric Disease and Treatment, vol. 15, pp. 511-521, 2019.

[27] V. H. Thourani, W. S. Weintraub, B. Stein et al., "Influence of diabetes mellitus on early and late outcome after coronary artery bypass grafting," The Annals of Thoracic Surgery, vol. 67, pp. 1045-1052, 1999.

[28] J. D. Newman, T. Wilcox, N. R. Smilowitz, and J. S. Berger, "Influence of diabetes on trends in perioperative cardiovascular events," Diabetes Care, vol. 41, pp. 1268-1274, 2018.

[29] M. Sari, H. Kilic, O. K. Ariturk, N. Yazihan, and R. Akdemir, "Diabetic patients have increased perioperative cardiac risk in heart-type fatty acid-binding protein-based assessment," Medical Principles and Practice : International Journal of the Kuwait University, Health Science Centre, vol. 24, pp. 53-57, 2015.

[30] T. R. Einarson, A. Acs, C. Ludwig, and U. H. Panton, "Prevalence of cardiovascular disease in type 2 diabetes: a systematic literature review of scientific evidence from across the world in 2007-2017," Cardiovascular Diabetology, vol. 17, p. 83, 2018.

[31] Q. Liu, D. Chen, Y. Wang, X. Zhao, and Y. Zheng, "Cardiac autonomic nerve distribution and arrhythmia," Neural Regeneration Research, vol. 7, pp. 2834-2841, 2012.

[32] S. A. Little, W. R. Jarnagin, R. P. DeMatteo, L. H. Blumgart, and Y. Fong, "Diabetes is associated with increased perioperative mortality but equivalent long-term outcome after hepatic 
resection for colorectal cancer," Journal of gastrointestinal surgery, vol. 6, pp. 88-94, 2002.

[33] K. Hughes, J. D. Jackson, T. I. Prendergast et al., "Diabetes mellitus is not associated with major morbidity following open abdominal aortic aneurysm repair," The Journal of Surgical Research, vol. 184, pp. 751-754, 2013.

[34] A. Ata, B. T. Valerian, E. C. Lee, S. L. Bestle, S. L. Elmendorf, and S. C. Stain, "The effect of diabetes mellitus on surgical site infections after colorectal and noncolorectal general surgical operations," The American Surgeon, vol. 76, pp. 697-702, 2010.

[35] M. Krolikowska, M. Kataja, R. Poyhia, J. Drzewoski, and M. Hynynen, "Mortality in diabetic patients undergoing non-cardiac surgery: a 7-year follow-up study," Acta Anaesthesiologica Scandinavica, vol. 53, pp. 749-758, 2009. 